\title{
Reducing barriers to accessing fistula repair: Implementation research in Uganda
}

Justus Barageine

Charity Ndwiga

Population Council

Hassan Kanakulya

Pooja Sripad

Population Council

Follow this and additional works at: https://knowledgecommons.popcouncil.org/departments_sbsr-rh

Part of the International Public Health Commons, Maternal and Child Health Commons, Obstetrics and Gynecology Commons, Social and Behavioral Sciences Commons, and the Women's Health Commons How does access to this work benefit you? Let us know!

\section{Recommended Citation}

Barageine, Justus, Charity Ndwiga, Hassan Kanakulya, and Pooja Sripad. 2019. "Reducing barriers to accessing fistula repair: Implementation research in Uganda," Fistula Care Plus Brief. Population Council. 


\section{REDUCING BARRIERS TO ACCESSING FISTULA REPAIR: IMPLEMENTATION RESEARCH IN UGANDA}

\section{BACKGROUND}

Female genital fistula is preventable and surgically treatable, but women who lack access to quality healthcare often live with fistula for many years. In Uganda, about two percent of women aged 15-49 years report having experienced fistula-like symptoms, with the highest prevalence occurring in the western region. Despite the implementation of fistula camps in tertiary hospitals in Uganda, many women remain unrepaired.

Formative research conducted in 2015 highlighted barriers hindering access to fistula care services, including a lack of knowledge about fistula among lower level providers and women and their families; transportation and financial costs; fear and stigma; weak community and facility referral systems; and lack of counseling services for women and communities.

\section{IMPLEMENTATION RESEARCH}

Population Council, in collaboration with Fistula Care Plus (FC+) and EngenderHealth conducted implementation research to understand whether a comprehensive information, screening, and referral intervention reduces transportation, communication, and financial barriers to accessing fistula screening, diagnosis, and treatment in Uganda. Following a baseline assessment, researchers implemented a multi-pronged intervention utilizing a mobile hotline, transport voucher, and mass media tools to increase community awareness. The study was conducted in one intervention (Kalungu) and one comparison (Masaka) district in Central-1 sub-region. The 12-month intervention convened an initial training of 42 primary health center (PHC) providers and 275 community agents to better identify and refer women with fistula. Twenty-three PHC providers and 216 community agents received a refresher training following midline data collection, and an endline evaluation occurred after the intervention (Figure 1).

\section{Highlights}

- Implementation of a mobile hotline, community volunteers, job aids at primary health centers, and transport vouchers increased referrals and access to fistula repair services at specialized centers.

- More primary healthcare providers at endline recognize and refer fistula patients, though knowledge gaps and turnover remain.

- Fewer psychological, transportation, and financial barriers, and beliefs of supernatural causes of fistula were observed.

- The hotline and communityto-facility referrals improved access to fistula services for stigmatized populations.

- Health systems and external stakeholder support are essential for sustaining trends.

\section{FIGURE 1: TIMELINE OF ACTIVITIES}

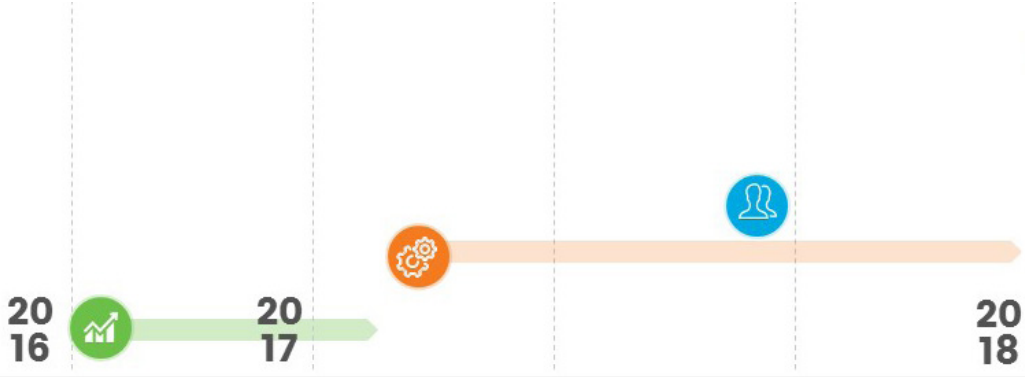

$$
\begin{aligned}
& \text { Intervention } \\
& \text { July } 2017 \text { - June } 2018
\end{aligned}
$$

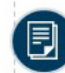

18
The Population Council conducts research and delivers solutions that improve lives around the world.

Big ideas supported by evidence: It's our model for global change. popcouncil.org (c) 2019 The Population Council, Inc.
Midline Data Collection November - December 2017

\section{Endline Data Collection July - October 2018}


FC+ partnered with Viamo to develop a free mobile hotline to sureen women for fistula using interactive voice response (IVR) technology. Information education and communications (IEC) materials were developed, contextualized to the Ugandan setting, and disseminated throughvaried community channels (radio, billboards, posters). The hotline reach was district-wide.

\section{Community outreach agents:}

2-day training for village health team members (VHTs) in Kalungu district. In addition to quarterly support supervision visits, following midline feedback a two-day refresher training bolstered comprehension of Job Aids and IEC materials, screening algorithm, the transportvoucher and monitoring tools, relationships with PHC providers and other stakeholders, and emphasized the intervention's role in prevention, treatment and referral for fistula patients.

\section{Primary health care (PHC) providers:}

3-day training for PHCproviders in Kalungu district. In addition to quarter ly support supenvicion visits, following midline feed back a two-day refresher training bolsteredcomprehension of tob Aids andIEC neteri rerials, screening algorithm, the transport voucher and monitoring tools, relationships with community volunteers and other stakeholders, and emphasized the intervention's role in prevention, treatment and referral for fistula patients.

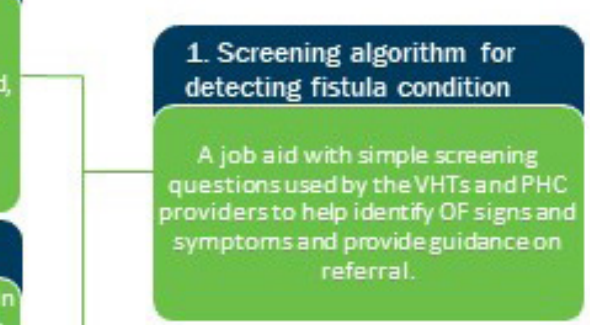

1. Transport voucher for

suspected fistula cases to

fistula repair center

VHTs and PHC providers followed-up with positively sueened women \& facilitated freetransport to thefistula treatment facility using a

transportation voucher designed for

intervention. In areas wherethe transport voucher was not used, free transport was still arranged given the mobile hot line reach.

\section{Intervention}

The intervention, implemented by FC+, used a "3-1-1" model that applied three communication channels for messaging, one screening algorithm for screening at the $\mathrm{PHC}$, and one transport voucher enabling access to a fistula repair center, located at Kitovu Mission Hospital in Masaka District, for diagnosis and repair.

The primary model of fistula repair care in Uganda is the use of hospital-facilitated fistula camps, held periodically throughout the year during which women referred to the hospital receive repair treatment.

\section{TABLE 1: DATA COLLECTION ACTIVITIES}

\section{Methods and Data Sources}

Mixed methods were used to investigate:

(a)Intervention outcomes, including fistula repair referrals, provider knowledge and practice, women's fistula status, barriers and enablers to care, and community awareness of fistula causes and care options

(b) Challenges, successes, and sustainability implications for screening and referral at community and PHC levels using the hotline, job aides, and transport vouchers.

Data collection activities in Kalungu (intervention) and Masaka (comparison) districts at baseline, midline, and endline are outlined in Table 1.

\begin{tabular}{|c|c|c|c|c|}
\hline Method & Purpose & Baseline & Midline & Endline \\
\hline Assessment of PHC facility & $\begin{array}{l}\text { Assessed health system capacity \& contextualized intervention } \\
\text { setting }\end{array}$ & 50 & $\mathrm{n} / \mathrm{a}$ & 48 \\
\hline $\begin{array}{l}\text { Assessment of Fistula } \\
\text { Center }\end{array}$ & Tracked referrals and surgeries & 1 & $n / a$ & 1 \\
\hline Survey of PHC providers & $\begin{array}{l}\text { Assessed knowledge, attitudes, and operational challenges } \\
\text { around intervention implementation }\end{array}$ & 144 & $n / a$ & 107 \\
\hline $\begin{array}{l}\text { Survey of post-repair } \\
\text { women }\end{array}$ & Explored fistula history, experience of barriers and enablers & 96 & $\mathrm{n} / \mathrm{a}$ & 47 \\
\hline $\begin{array}{l}\text { In-depth interview with key } \\
\text { stakeholders: } \\
\text { - VHTs } \\
\text { - VHT coordinators } \\
\text { - PHC providers } \\
\text { - Fistula center staff } \\
\text { - District health managers } \\
\text { - FC+ Uganda staff } \\
\text { - Post-repair clients }\end{array}$ & $\begin{array}{l}\text { Content validated barrier index among women living with fistula } \\
\text { at baseline; } \\
\text { and } \\
\text { Explored experiences of the implementation process from } \\
\text { implementers' and stakeholders' perspectives at midline and } \\
\text { endline }\end{array}$ & $27 *$ & 16 & 18 \\
\hline $\begin{array}{l}\text { Focus group discussion } \\
\text { (FGD) with community } \\
\text { men and women }\end{array}$ & $\begin{array}{l}\text { Explored barriers and enablers to accessing care and } \\
\text { normative attitudes toward fistula causes and consequences }\end{array}$ & 6 & $\mathrm{n} / \mathrm{a}$ & 8 \\
\hline
\end{tabular}


FIGURE 2: NUMBER OF FISTULA ADMISSIONS, SURGERIES, SCREENING AND REFERRALS

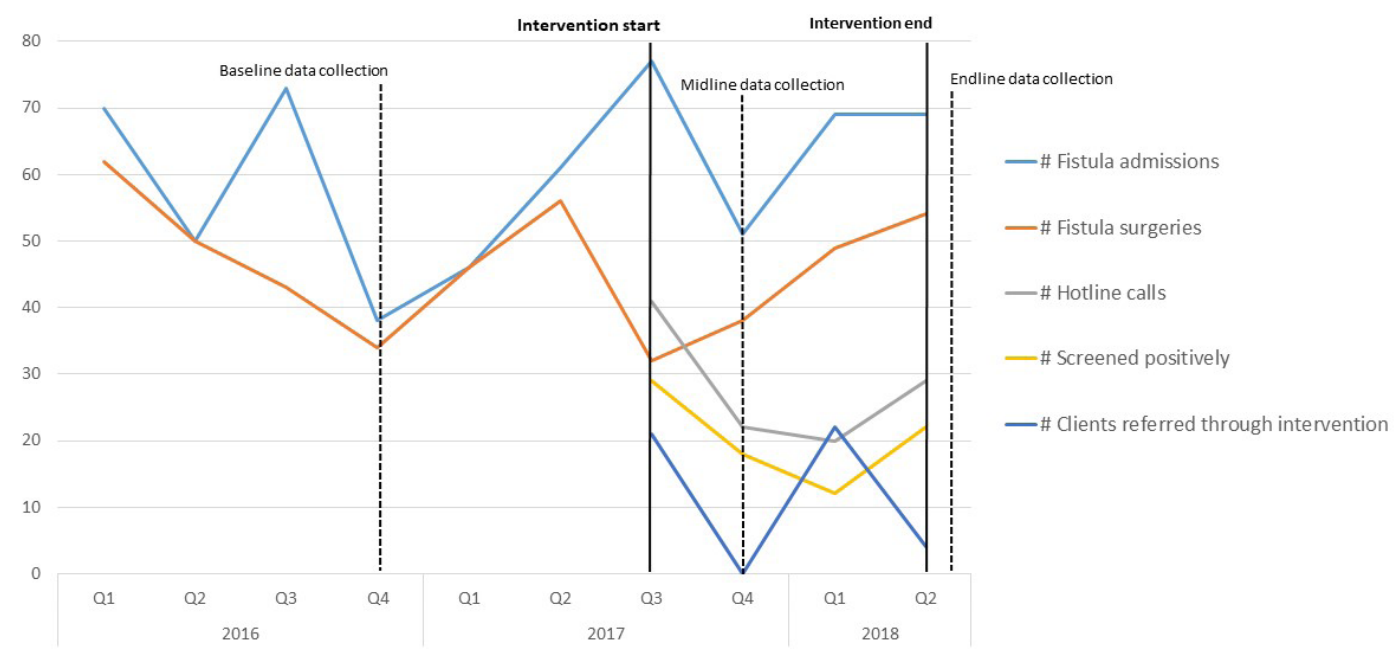

\section{FINDINGS}

\section{Facility Assessments}

PHC facility ownership remained constant from baseline to endline; approximately $70 \%$ of the sample facilities were publicly-owned. Unsurprisingly, the majority of the PHC workforce was comprised of nurses/ midwives, nursing officers, and nurse assistants. There was varied availability and functionality of basic commodities at sample facilities including electricity, generators, running water, toilets, and private delivery rooms; these figures remained consistent at baseline and endline. PHC facility surveys showed increased referral from almost none prior to the intervention to about ten referrals per quarter during the intervention.

Figure 2 presents suspected fistula cases and surgeries from baseline and endline assessments and program monitoring statistics. Despite trends showing a slow start to intervention uptake with initial decreases in numbers of fistula admissions, the number of hotline calls made and subsequent positive screenings and referral of women with fistula increased following midline data collection, likely due to refresher trainings. In addition to women with suspected fistula who arrived at the fistula repair center, women experiencing similar conditions such as uterine or rectal prolapse or third-degree pelvic tears were managed during camps. Women presenting with similar conditions may account for the overall lower

\section{FIGURE 3: FISTULA RECOGNITION \& CARE PRACTICES OF PHC PROVIDERS (\%)}

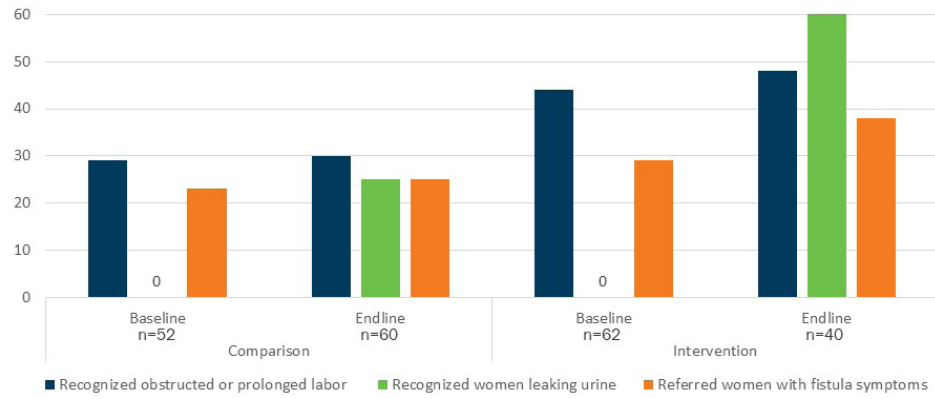

number of women screened positive and referred through the intervention. Program data do not capture the number of women calling from outside the intervention district.

\section{Monthly Program Monitoring Statistics}

Monthly program data, monitored by collaborating partner, Viamo, tracked the number of calls made to the hotline and the number of client callers subsequently referred to the fistula repair center. In the 12 months preceding the intervention, 315 women sought care for fistula symptoms at the fistula repair center, while 419 women sought care during the study intervention period, representing a 33\% increase. Overall, 589 women from the intervention area called the hotline and 114 were screened positively for fistula. Of these 114 women, 43 used the transport voucher component of the intervention to reach 93 diagnosis and repair visits to the fistula repair center. The increase of women seeking care for fistula during the intervention, compared to the preceding year, provides insight into both the intervention success and general community trends for seeking fistula care.

\section{TABLE 2: FISTULA REPAIR CLIENT SURVEY}

\begin{tabular}{|l|l|l|}
\hline Fistula experience indicator & $\begin{array}{l}\text { Baseline } \\
\mathrm{n}=96(\%)\end{array}$ & $\begin{array}{l}\text { Endline } \\
\mathrm{n}=47(\%)\end{array}$ \\
\hline $\begin{array}{l}\text { Clients who began leaking post- } \\
\text { delivery (obstetric fistula) }\end{array}$ & $84(87.5)$ & $46(97.9)$ \\
\hline $\begin{array}{l}\text { Obstetric fistula cases following } \\
\text { normal delivery }\end{array}$ & $28(33.3)$ & $16(34.8)$ \\
\hline $\begin{array}{l}\text { Years clients lived with fistula } \\
\text { (any sort) }\end{array}$ & $\begin{array}{l}\text { Mean: } \\
5.9 \text { yrs; } \\
\text { Range: }\end{array}$ & $\begin{array}{l}\text { Mean: } \\
4.1 \text { yrs; } \\
\text { Range: } \\
0.2-20 \text { yrs }\end{array}$ \\
\hline $\begin{array}{l}\text { Attempts to seek fistula } \\
\text { treatment (\#) }\end{array}$ & $\begin{array}{l}\text { Mean: 3; } \\
\text { Range: }\end{array}$ & $\begin{array}{l}\text { Mean: } 2 ; \\
\text { Range: } \\
0-5\end{array}$ \\
\hline Women who have previously & 52 & $\begin{array}{l}28 \\
\text { (59.6) }\end{array}$ \\
\hline
\end{tabular}




\section{PHC Providers}

Endline surveys took place with 60 and 40 providers in comparison and intervention communities, respectively. Findings were compared to baseline survey data from 52 and 62 comparison and intervention providers, respectively. PHC providers demonstrated significant increases in recognition of fistula causes and symptoms following the intervention and subsequently made more referrals for repair. Providers in intervention facilities better recognized prolonged and obstructed labor at endline than at baseline (68\% vs. $23 \%$ prolonged labor recognition at endline vs. baseline, respectively; $75 \%$ vs. $56 \%$ obstructed labor recognition at endline vs. baseline, respectively). Conversely, providers in comparison facilities showed a decrease in recognition of both prolonged and obstructed labor at endline compared to baseline (27\% vs. 31\% prolonged labor recognition at endline vs. baseline, respectively; $38 \%$ vs. $60 \%$ obstructed labor recognition at endline vs. baseline, respectively).

At baseline, few providers recognized leaking urine or feces as a danger sign of fistula, but, at endline, $60 \%$ of providers in intervention facilities recognized these signs $(p<0.001)$. At endline, providers in comparison facilities recognized leaking urine and feces 25\% ( $p<0.001)$ and $13 \%(p=0.020)$ of the time, respectively. In both intervention and comparison facilities, slightly more providers made referrals for fistula repair care at endline than at baseline (38\% vs. 29\% in intervention facilities, respectively; $25 \%$ vs. $23 \%$ in comparison facilities, respectively). See Figure 3 for detail.

\section{Fistula Repair Clients}

At baseline, of the 96 women surveyed at Kitovu Mission Hospital, 43.8\% were between $15-29$ years of age, $40.6 \%$ were married, $88.5 \%$ were Christian and $11.5 \%$ were Muslim. Eighty-seven percent had formal public education (21.8\% completed secondary or tertiary education) and $58.3 \%$ ever worked for an income. At endline, of the 47 women surveyed, $46.8 \%$ were between $15-29$ years of age, $21.3 \%$ were married, $85.1 \%$ were Christian and $10.6 \%$ were Muslim. More than 95\% had any formal public education (21.3\% completed secondary or tertiary education) and 53.2\% ever worked for an income. At baseline and endline, approximately $80 \%$ of the women surveyed came from outside the Central-1 sub-region.

On average, there was slight reduction in the number and range of years women lived with fistula and in the frequency of previous fistula treatment seeking between baseline and endline. Though women continue to seek treatment for fistula multiple times, the average number of attempts slightly decreased over the intervention period and there is less variability, suggesting improved access to care (Table 2).

\section{Barriers to Care}

Survey results (Table 3) show that the stigma and shame associated with uncontrollably leaking in public can lead to psychological barriers to care-seeking among women. More women at endline reported having a support system to accompany them to the fistula camp and fewer women reported feeling isolated or embarrassed about their

\section{TABLE 3: BARRIERS TO ACCESSING FISTULA REPAIR}

\section{Barrier Index}

\begin{tabular}{|c|c|c|c|c|}
\hline index & Gaver & (0) & 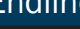 & $1=$ \\
\hline & $\mathrm{n}$ & $\%$ & $\mathrm{n}$ & $\%$ \\
\hline I did not know that fistula is a medical condition that can be treated. & 78 & 81.3 & 31 & 66.0 \\
\hline I did not know where to go for fistula repair. & 79 & 82.3 & 35 & 74.5 \\
\hline I was told by health providers (in the past) that my fistula will heal itself. & 7 & 7.3 & 8 & 17.0 \\
\hline I was told by health providers (in the past) that my fistula cannot be treated. & 8 & 8.3 & 5 & 10.6 \\
\hline I did not have money to pay for medical care to treat my fistula. & 87 & 90.6 & 44 & 93.6 \\
\hline The cost of transportation to repair sites and accommodation was too high. & 60 & 62.5 & 35 & 74.5 \\
\hline I fear traveling to the health facility because of pain/discomfort during travel. & 49 & 51.0 & 20 & 42.6 \\
\hline I did not have someone to support me in seeking/reaching care. & 43 & 44.8 & 14 & 29.8 \\
\hline I felt embarrassed because of my fistula condition. & 90 & 93.8 & 45 & 95.7 \\
\hline I felt isolated because of my fistula condition. & 67 & 69.8 & 45 & 95.7 \\
\hline I was afraid of harsh treatment by providers at the fistula repair center/ camp. & 48 & 50.0 & 19 & 40.4 \\
\hline I felt ashamed of having obstetric fistula. & 89 & 92.7 & 42 & 97.9 \\
\hline I felt worthless. & 81 & 84.4 & 38 & 91.5 \\
\hline I felt am not as complete as a person because of fistula. & 90 & 93.8 & 42 & 91.5 \\
\hline I believed that my fistula was caused by diabolic means. & 55 & 57.3 & 26 & 40.4 \\
\hline Once others learnt of my condition, they did not allow me to work/earn money. & 54 & 56.3 & 25 & 48.9 \\
\hline I felt embarrassed about smell/leaking while travelling to facility. & 68 & 70.4 & 32 & 66.0 \\
\hline
\end{tabular}


condition. Despite the intervention, women continued to perceive costs of medical care and transportation as barriers to care. Some reduction in access barriers was seen at endline; $34 \%$ of women said they knew fistula was a medical condition that could be treated, compared to only $19 \%$ at baseline. Slightly more women knew where to go for fistula repair at endline than at baseline (25\% compared to 18\%). Some awareness barriers remained, however, particularly at the provider level, as women continued to report being told that their fistula would heal itself or could not be treated.

\section{INTERVENTION PROCESSES, CHALLENGES, AND SUCCESSES}

\section{Training}

Initial and refresher trainings were applicable and effective in enhancing PHC providers' and VHTs' efforts to educate and sensitize community members on fistula; in helping women with fistula overcome stigma barriers; and in linking women to care and treatment.

"After the training, I have improved on my knowledge that in case a person develops a problem, she has to seek medical attention beyond the health facility where she developed the problem from."

$-\mathrm{VHT}$, intervention site, endline

Providers demonstrated a clear understanding of the $\mathrm{FC}+$ barrier reduction intervention and their expected role(s) in project activities. VHT coverage and provider referral capacities worked complementarily to overcome challenges of identifying and referring fistula patients from remote areas.

\begin{abstract}
"Prior to the intervention, it was difficult for staff to visit every village to identify those patients. But when the training was done it was helpful...because we needed these people. If the VHT identifies the patient, she is taken to the facility and screened..."
\end{abstract}

-Health manager, intervention site, endline

\section{Hotline}

Most stakeholders (including FC+ staff, local health managers, women clients, VHTs and PHC providers) reported at midline and endline that the hotline was an effective innovation for screening patients. It was instrumental in providing fistula-related information to women, allowing them to self-screen, and referring them to PHCs and treatment facilities.

"With that hotline, they give you directions properly and you don't lose track. It helps women because it gives them directives... there is a health worker who responds

to you and tells you to go to Kitovu like this and that."

$-\mathrm{VHT}$, intervention site, midline
VHTs and women reported some limitations of using the hotline, including lack of network coverage, low connectivity, confusion related to the interactive voice response (IVR), and a few instances of incomprehension.

"The network in our villages is a problem, so one might call the hotline and the network fails which becomes a problem... one patient has been calling now for a week; the number is not available." -Driver, intervention site, endline

"I was about to lose hope. I wondered why we cannot get to people and instead only the computer voices." -Post-repair client, intervention, endline

\section{Job Aids}

The forms used by PHC providers to screen women at health facilities or treatment centers are useful and assist $\mathrm{PHC}$ providers to identify fistula cases, make appropriate referrals, and give health education and counseling. They guide providers to counsel about fistula symptoms and treatment, describe what to expect from the FC+ intervention, and manage women's post-repair recovery.

"The job aid clearly outlines the causes of fistula, how to prevent it and seek treatment. Even though personally I haven't filled in the form, it helps me to train [myself and patients] on that problem."

-PHC provider, intervention site, endline

Although VHTs in the community and at health facilities distribute information, education, and counseling (IEC) materials, such as flyers, promoting the hotline number, gaps in coverage persist.

"This time when we went to Kitovu, they had made announcements over the radio. There is a VHT who came and told me, "There are some flyers they have sent us which have some numbers which you can come and get and try to call them... and I called them."

-Hotline user, intervention site, midline

\section{Information Channels}

At baseline, post-repair women acted as channels of important information for women seeking fistula repair options. Peer-to-peer information-sharing continued at endline and many post-repair clients offered to personally serve as conduits of information within their communities.

"I got in touch with a lady from our village who had a successful repair from this place. She told me that the repairs are free; they even refund you your transport... I got impressed and prepared to come."

-Post-repair client, comparison site, baseline

Most post-repair women at midline and endline reported hearing about repair surgery at Kitovu Mission Hospital through radio announcements. A few described learning of free repairs from friends or family members, while others 
said they were referred by PHC providers. Respondents consistently mentioned VHTs/community meetings as a preferred channel to disseminate information.

"We heard the announcement on the radio about the repairs in Kitovu hospital. We came with my husband plus my mother using public transport means."

-Post-repair client, comparison site, endline

\section{Transport Voucher}

The transport vouchers were useful to transport officers, PHC providers, and women themselves.

"In the training they taught us about the voucher, illustrating that we would distribute them... they contain an MTN number on which the PHC provider first sends a message that she has received a fistula client and it also has our contacts as taxi operators."

-Transport officer, intervention site, midline

However, women were unable to consistently use transport vouchers due to infrastructural and seasonal challenges leading to poor road conditions.

"The problem is our village leaders are not responsible. Our roads are very poor, you may call a special hire to take you to hospital and he tells you he cannot come because the roads are very bad."

-Female FGD participant, intervention site, endline

"The ministry should avail an ambulance as well as install a telephone service between health facilities and the referral centers for PHC workers to call ahead when sending fistula clients for surgery."

-Health Manager, comparison site, endline

\section{Health Policy \& Systems Environment}

Structural factors affecting implementation and sustainability of intervention efforts include policy changes in community health programming in Uganda and political processes that influence the PHC providerclient interaction. Challenges to the maintenance of the VHT program in Uganda create multiple barriers to ensuring community access to effective education and sensitization around fistula and women's access to fistula treatment. VHTs are a critical component of the health system, providing prevention and treatment information and facility referrals; dispelling myths and misconceptions about fistula; and empowering women to make informed health decisions.

"The government should strengthen the VHT system to make sure that they continue having ideas of identifying women within the community and also sensitizing about prevention. I think that will be sustainable." -FC+ staff, intervention site, midline
"They [VHTs] feel betrayed by their own government because they have been doing voluntary work and now it reaches a time when [government] are saying they no longer need them. It's affecting their work."

-FC+ staff, intervention site, endline

Political affiliations further influence the health system at the provider level where some PHC providers are perceived as uncaring towards women seeking fistula treatment - by denying care - based on political party affiliation or preference.

"The doctors tell you, 'After all, you're the people that elected him to power and you want him to stay long, so go and buy the medicine...' Sometimes if you come dressed in yellow a colour associated with a particular political party\} you are chased from the hospital."

-Female FGD participant, intervention site, endline

Shifting the fistula treatment model to a routine system may overcome the persistent barrier expressed by women around the timing of fistula camps and delayed or early arrivals to Kitovu when the camps are not in progress. Multiple women who heard about the free repair services on the radio remained unclear about the camp's timing and either missed the camp or arrived too early and were told to return at a later date.

"When I had been brought here to Kitovu hospital for treatment after delivery in Masaka, where I had a problem, I was told to come back on the dates when the camp would start."

-Post-repair client, endline

Increasing PHC and hospital provider capacity is required to sustain routine fistula repair in Uganda.

\section{CONCLUSIONS}

Reductions in some financial, transportation, awareness, and psychosocial barriers followed the implementation of the 3-1-1 intervention. Increases in admissions and surgeries at the fistula treatment center coincided with intervention activities, though the periodicity of the pooled/camp-based model made this difficult to capture. Program monitoring data suggest the hotline a) generated a large frequency of callers and b) demonstrated increases over the intervention period in the proportion of callers who sought fistula care as well as in the number of callers from the intervention areas. Transport voucher use also suggests women were emboldened to make diagnosis and repair trips during the intervention period.

Improvements were observed in PHC providers' recognition of fistula danger signs and symptoms, and subsequent referrals increased during the project implementation. Continued training around fistula screening and counseling could sustain improvements in 
provider referrals and further increase treatment access. Though women continue to seek treatment for fistula multiple times, the average number of attempts slightly decreased over the intervention period and there is less variability, suggesting improved efficiency in treatment access. While little change was reported in women's experience of psychosocial barriers to care, improvements in women's knowledge that fistula can be treated, and reductions in their feelings of embarrassment and fear around traveling to a facility for care are noted. Moderate improvement in women's feelings around being able to access care is an important first step in better linking women to fistula repair facilities.

Despite having heard about free repairs through multiple channels, women continue to perceive costs of medical care and transportation as barriers to access. Gaps in $\mathrm{PHC}$ provider knowledge and counseling practices persist following the intervention as women continue to report being told that their fistula will heal itself or cannot be treated.

Mass media, mobile hotline, and VHT intervention channels improved awareness, referral and access to the fistula treatment center (Kitovu Mission Hopsital) for diagnosis and subsequent repair visits. Women and community members report that radio and television were the most preferred source of information about fistula treatment. The mobile hotline and transport voucher were considered useful to women, particularly, when VHTs and providers facilitated access to fistula treatment in an integrated and timely way. Intermittent network connectivity and insufficient flyers posed challenges to intervention implementation.

Study limitations reflect the challenge of measuring the effects of complex interventions in a real-world setting. The inability to isolate districts as purely intervention or comparison, due to the hotline coverage throughout Kalungu district, limited researchers' ability to attribute observed changes to a component(s) of the intervention.

Researchers did not interview women living with fistula before they sought care or before they received repair and given the rarity of the condition at the population level, faced challenges recruiting post-repair women at endline. Provider surveys were cross-sectional; longitudinal designs would have increased the ability to make claims to causality around provider knowledge and practice but were not feasible for pragmatic reasons, including turnover and intervention training selection.

\section{KEY MESSAGES \& RECOMMENDATIONS}

- A multipronged intervention can be effective in reducing barriers to fistula treatment, but government and stakeholders must ensure a supportive environment for sustainability, including exploring routine models of fistula care.

- Trained PHC providers facilitated with adequate job aids can screen and refer fistula patients thus reducing delays in accessing treatment previously reported by women in the region.

- Radio, hotline and VHTs are the preferred sources of information at community level to provide prevention and treatment information.

- Perceived benefits of transport vouchers include women feeling more comfortable traveling to health facilities and having an accompaniment to do so, but infrastructural barriers persist, especially for women in the most remote areas.

- Integrated fistula policy and programming requires engagement of VHTs, media sources, and PHCs within the context of the shifting community health strategy.

\section{CONTACT}

\author{
Justus Barageine \\ Makerere University, Uganda \\ barageinej@gmail.com
}

\author{
Charity Ndwiga \\ Population Council, Nairobi, Kenya \\ cndwiga@popcouncil.org
}

\author{
Hassan Kanakulya \\ EngenderHealth, Uganda \\ hkanakulya@engenderhealth.org
}

\author{
Pooja Sripad \\ Population Council, Washington D.C., USA \\ psripad@popcouncil.org
}

